\title{
RAÇÃO DE FARELO DE SOJA E DE FARELO INTEGRAL EXTRUSADA E DIFERENTES NÍVEIS DE SUBSTITUIÇÃO DO MILHO POR TITRICALE NA ALIMENTAÇÃO ANIMAL. II. DESEMPENHO NO CRESCIMENTO E NA TERMINAÇÃO DE SUÍNOS
}

\section{LUIZ MÁRIO FEDALTO ${ }^{1}$; GIOVANA LAÍS RUVIARO TULESKI ${ }^{2}$; MARSON BRUCK WARPECHOSKI ${ }^{3}$; CLARICE RIEKES ${ }^{4}$}

\author{
1,3 Departamento de Zootecnia do Setor de Ciências Agrárias; ${ }^{2}$ Acadêmica de Medicina Veterinária; \\ ${ }^{4}$ Acadêmica de Engenharia Agronômica da Universidade Federal do Paraná, Bolsistas do Programa \\ Institucional de Bolsas de Iniciação Científica - PIBIC-CNPq.
}

\begin{abstract}
Rations containing two sources of proteins, soybean meal and extruded soy seeds, and 5 levels $(0,25,50,75$ and $100 \%)$ of substitution of the corn by triticale were evaluated in experiments performed to study the growing and finishing behavior of swine's. Extruded soy been seeds' diet showed the lower average gain weight and feed consumption $(p<0.05)$ in the total period of the experiment. Corn substitution at 0 and $50 \%$ displayed a higher slaughter weight in spite of the fact that the feed efficiency was not different between these levels $(p<0.05)$. It may be concluded that by introducing a correction in the diets' energy values, the substitution of maize by triticale is viable.
\end{abstract}

RESUMO - Foram avaliadas duas fontes de proteína, farelo de soja e soja integral extrusada, e 5 níveis de substituição $(0,25,50,75$ e 100\%) do milho pelo triticale, em rações para suínos em crescimento e terminação. Considerando-se o período total, ganho de peso e consumo diários de ração foram menores $(\mathrm{P}<0,05)$ nas dietas à base de soja integral extrusada, não correspondendo às expectativas. $\mathrm{O}$ peso ao abate foi maior em 0 e $50 \%$ de substituição, mas a conversão alimentar não diferiu $(\mathrm{P}>0,05)$ entre os níveis. Conclui-se que, corrigindo-se a energia, a substituição total do milho por triticale é viável.

\section{Introdução}

A soja integral extrusada e o triticale são fontes alternativas de proteína e energia, podendo ocupar papéis de destaque na busca pela redução dos custos com alimentação de suínos.

Através do processo de extrusão, os fatores antinutricionais existentes na soja crua são inativados, o que viabiliza a substituição do farelo de soja pela soja integral extrusada em rações para não-ruminantes.

O triticale pode substituir o milho na formulação de rações, uma vez que possui teores médios de proteína bruta, lisina, energia digestível e metabolizável para suínos $(12,50 ; 0,39 \% ; 3.320$ e $3.180 \mathrm{kcal} / \mathrm{kg}$, respectivamente) muito próximos aos do milho $(8,3 \%$; $0,26 \% ; 3.525$ e $3.420 \mathrm{kcal} / \mathrm{kg}$ ) (NRC, 1998). Alguns autores sugeriram que o menor valor energético do triticale pode limitar a sua utilização (MILLER e ERICKSON, 1980) e piorar a conversão alimentar dos suínos (HALE e UTLEY, 1985). Entretanto, a energia pode ser corrigida através da adição de óleo vegetal às rações (FURLAN et al., 1997). Além disso, devido ao seu maior teor de proteína bruta e melhor perfil de aminoácidos, o triticale pode substituir, além do milho, parte da fonte protéica (farelo de soja ou soja extrusada).

$\mathrm{O}$ uso de triticale em rações para suínos em crescimento e terminação tem sido estudado por diversos autores. FERREIRA et al. (1992), HALE e UTLEY (1985), e MYER et al. (1989) evidenciaram que a substituição de $100 \%$ do milho não prejudica o desempenho dos animais. O mesmo não foi observado por MYER e BARNETT (1985), COFFEY e GERRITS (1988) e GALÁNTAI et al. (1998) que verificaram piora na conversão alimentar com a substituição total do milho. Já os resultados obtidos por BRAND et al. (1995) evidenciaram que a substituição do milho por triticale não interfere na conversão alimentar de suínos em crescimento e terminação, diminuindo, entretanto, o ganho de peso diário.

O objetivo desse experimento foi avaliar os efeitos da utilização da soja integral extrusada e do triticale sobre o desempenho de suínos nas fases de crescimento e terminação.

\section{Materiais e Métodos}

Foram utilizados 60 leitões mestiços Landrace $\mathrm{x}$ Large White, ou Landrace x Moura ou Large White $\mathrm{x}$ Moura, que ao início do experimento pesavam em média $27,99 \mathrm{~kg}$, terminando a fase de crescimento com $57,87 \mathrm{~kg}$ e sendo abatidos com peso médio de $97,60 \mathrm{~kg}$, num delineamento experimental em blocos casualizados, em esquema fatorial $2 \times 5$, sendo os fatores duas fontes de proteína, farelo de soja (FS) e soja integral extrusada (SE) e cinco níveis de substituição do milho pelo triticale $(0,25$, 50,75 e $100 \%$ ), com seis repetições por tratamento.

Os animais receberam rações isoprotéicas e isoenergéticas durante as fases de crescimento e terminação, contendo 16 e 14\% de proteína bruta, e 3300 e $3150 \mathrm{kcal} / \mathrm{kg}$, respectivamente. 
Foram feitas pesagens a cada 14 dias, para que as trocas de ração ocorressem quando os animais chegassem aos $57 \mathrm{~kg}$. Foram controlados todos os fornecimentos, perdas e as respectivas sobras, obtendo-se o consumo diário de ração dos animais.

Os resultados foram submetidos à análise de variância através do método dos quadrados mínimos para dados com números desiguais de subclasses, utilizando-se o programa SAEG Sistema para Análises Estatísticas e Genéticas desenvolvido por EUCLIDES (1983). As médias dos tratamentos foram comparadas pelo teste de NEWMAN KEULS a $5 \%$ e os níveis de substituição de milho pelo triticale foram desdobrados em contrastes ortogonais com o objetivo de ser estudada a regressão desta característica até o terceiro grau.

\section{Resultados e Discussão}

O ganho de peso e o consumo foram superiores $(\mathrm{P}<0,05)$ para os tratamentos que receberam $\mathrm{FS}$ $(0,796$ e $2,42 \mathrm{~kg})$ em relação à $\mathrm{SE}(0,750$ e $2,25 \mathrm{~kg})$ e a conversão alimentar não diferiu $(\mathrm{P}>0,05)$ entre as fontes 3,04 e 2,96), respectivamente. $\mathrm{O}$ efeito de níveis, independentemente de fontes, foi superior $(\mathrm{P}<0,05)$ no ganho de peso diário para o NS-50 $(0,838 \mathrm{~kg})$, intermediário no NS-0 $(0,793 \mathrm{~kg})$ e inferior no NS-25, 75 e 100 com $(0,740 ; 0,751$; e, 0,742 ) respectivamente. Quando os valores foram avaliados nas fases de crescimento e/ou terminação, separadamente estas diferenças não apareceram. A mesma tendência ocorreu com relação ao consumo alimentar. Assim, os resultados das conversões alimentares não diferiram $\mathrm{P}>0,05)$ entre os tratamentos (Tabela 1).

Tabela 1. Médias referentes ao peso $(\mathrm{kg})$, ganho de peso diário $(\mathrm{kg})$, consumo diário $(\mathrm{kg})$ e conversão alimentar dos animais em relação aos níveis crescentes de substituição do milho por triticale $(0,25,50,75$ e $100 \%)$ e em relação à fonte protéica ( $\mathrm{FS}=$ farelo de soja; $\mathrm{SE}=$ soja extrusada).

\begin{tabular}{|c|c|c|c|c|c|c|c|c|}
\hline \multirow[t]{2}{*}{ Características } & \multicolumn{5}{|c|}{ Níveis de substituição (NS) } & \multicolumn{2}{|c|}{ Fonte protéica } & \multirow{2}{*}{$\begin{array}{l}\text { Média } \\
\text { Geral }\end{array}$} \\
\hline & $0 \%$ & $25 \%$ & $50 \%$ & $75 \%$ & $100 \%$ & $\mathrm{FS}$ & SE & \\
\hline \multicolumn{9}{|l|}{ Fase crescimento } \\
\hline Peso inicial & 27,77 & 27,95 & 28,23 & 27,82 & 28,19 & 27,98 & 28,01 & 27,99 \\
\hline Peso final & $59,11^{\text {ab }}$ & $56,66^{\mathrm{ab}}$ & $61,25^{\mathrm{a}}$ & $55,52^{\mathrm{b}}$ & $56,85^{\mathrm{ab}}$ & $59,51^{\mathrm{A}}$ & $56,24^{\mathrm{B}}$ & \\
\hline Ganho de peso diário & 0,810 & 0,731 & 0,841 & 0,719 & 0,752 & $0,815^{\mathrm{A}}$ & $0,726^{\mathrm{B}}$ & 0,771 \\
\hline Consumo diário & $2,12^{\mathrm{a}}$ & $1,95^{\mathrm{ab}}$ & $2,16^{\mathrm{a}}$ & $1,86^{\mathrm{b}}$ & $1,84^{\mathrm{b}}$ & $2,09^{\mathrm{A}}$ & $1,88^{\mathrm{B}}$ & 1,99 \\
\hline Conversão alimentar & 2,62 & 2,66 & 2,57 & 2,61 & 2,47 & 2,58 & 2,59 & 2,59 \\
\hline \multicolumn{9}{|l|}{ Fase terminação } \\
\hline Peso médio de abate & $101,31^{\mathrm{a}}$ & $94,44^{b}$ & $103,20^{\mathrm{a}}$ & $94,77^{b}$ & $94,28^{b}$ & $99,18^{\mathrm{A}}$ & $96,02^{\mathrm{B}}$ & 97,60 \\
\hline Ganho de peso diário & 0,842 & 0,754 & 0,835 & 0,786 & 0,752 & 0,790 & 0,797 & 0,794 \\
\hline Consumo diário & 2,78 & 2,66 & 2,77 & 2,66 & 2,44 & 2,72 & 2,60 & 2,66 \\
\hline Conversão alimentar & 3,23 & 3,50 & 3,27 & 3,36 & 3,20 & 3,40 & 3,23 & 3,31 \\
\hline \multicolumn{9}{|c|}{ Fase crescimento-terminação } \\
\hline Ganho de peso diário & $0,793^{\mathrm{ab}}$ & $0,740^{\mathrm{b}}$ & $0,838^{\mathrm{a}}$ & $0,751^{\mathrm{ab}}$ & $0,742^{b}$ & $0,796^{\mathrm{A}}$ & $0,750^{\mathrm{B}}$ & 0,773 \\
\hline Consumo diário & $2,46^{\mathrm{a}}$ & $2,32^{\mathrm{ab}}$ & $2,49^{\mathrm{a}}$ & $2,28^{\mathrm{ab}}$ & $2,14^{\mathrm{b}}$ & $2,42^{\mathrm{A}}$ & $2,25^{\mathrm{B}}$ & 2,34 \\
\hline Conversão alimentar & 2,97 & 3,14 & 2,97 & 3,04 & 2,88 & 3,04 & 2,96 & 3,00 \\
\hline
\end{tabular}

Médias com letras distintas variam significativamente $(\mathrm{P}<0,05)$ pelo teste de NEWMAN KEULS a 5\%.

Estes resultados estão de acordo com os de FERREIRA et al. (1992), HALE e UTLEY (1985), e MYER et al. (1989) que evidenciaram ser possível substituir em até $100 \%$ do milho pelo triticale sem prejudicar o desempenho dos animais. É contraditório em relação ao que foi observado por MYER e BARNETT (1985), COFFEY e GERRITS (1988) e GALÁNTAI et al. (1998) que verificaram pior conversão alimentar com a substituição total do milho. Já BRAND et al. (1995) evidenciaram, da mesma forma que o presente trabalho, que a substituição do milho por triticale não interferiu na conversão alimentar de suínos em crescimento e terminação, diminuindo, entretanto, o ganho de peso diário.

Pelos resultados, pode-se concluir que corrigindose a energia das dietas pela inclusão de óleo de soja, é possível substituir o milho pelo triticale em até $100 \%$. A fonte protéica a ser indicada estará em função do custo de cada ingrediente, farelo de soja, óleo e/ou soja integral extrusada.

\section{REFERÊNCIAS BIBLIOGRÁFICAS}

BRAND, T.S.; OLCKERS, R.C.; MERWE, J.P., van der; MERWE, J.P., van der. Triticale (Tritico secale) as substitute for maize in pig diets. Animal Feed Science and Technology, 53(3):345-352, 1995.

COFFEY, M.T.; GERRITS, W.J. Digestibility and feeding value of B858 triticale for swine. Journal of Animal Science, 66(11):2728-2735, 1988.

EUCLIDES, R. F. SAEG - Sistema de Análises Estatísticas e Genéticas. Viçosa. U.F.V., Central de Processamentos de Dados, 68p. 1982. 
Farelo de soja Extrusada vs Milho e Titricale no Crescimento e na Terminação de Suínos

FERREIRA, A.S.; LIMA, G.J.M.M.; ZANOTTO, D.L.; BASSI, L.J. Triticale como alimento alternativo para suínos em crescimento e terminação. Rev. Soc. Bras. Zoot., Viçosa, 21(2):300-308, 1992.

FURLAN, A.C.; MIKAMI, F.; MOREIRA, I.; SCAPINELLO, C.; MURAKAMI, E. A. Utilização do triticale (triticale turgidosecale) na alimentação de suínos em crescimento. In: REUNIÃO DA SBZ (34 : 1997 : Juiz de Fora). Anais. Juiz de Fora : SBZ, p.115-117, 1997.

GALÁNTAI, M.S.; HARCZI, I.Z.; HUSZÁR, S. Using 'Tewo' triticale in diets for fattening pigs. Állanyéstés és Takarmányozás, Hungary, v. 47, n.1., p. 49-57, 1998. Nutrition Abstracts \& Rewiews, Wallingford, 68(12):1143, dez, 1998. Ref. 7005. Resumo.

HALE, O.M.; UTLEY, P.R. Value of Beagle 82 triticale as substitute for corn and soybean meal in the diet of pigs. J. Anim. Sci., Champaign, 60(5):1272-1279, 1985.

MILLER, E.R.; ERICKSON, J.P. Triticale as an ingredient for pig diets. Pigs, Doetinchen, 1(3): 207-210, 1980.
MYER, R.O.; BARNETT, R.D. Triticale ("Beagle 82") as an energy and protein source in diets for starting and growing-finishing swine. Nutrition Reports International, 31(1):181-190, 1985.

MYER, R.O.; BARNETT, R.D.; CORNELL, J.A.; COMBS, G.E. Nutritive value of diets containing triticale and varying mixtures of trtiticale and maize for growing - finishing swine. Animal Feed Science and Technology, Amsterdam, 22(3):217225, 1989.

MYER, R.O.; BRENDEMUHL, J.H.; BARNETT, R.D. Synthetic amino acid supplementation of triticale and wheat based diets for growing-finishing pigs. Triticale: today and tomorrow. Gainesville, 1996. Nutrition Abstracts \& Reviews, Wallingford, 68(6), Ref. 3139. Resumo, 1998.

NATIONAL RESEARCH COUNCIL. Washington. Nutrients requirements of swine. 10. ed. Washington: National Academy Press, 189 p., 1998. 